\title{
Oxidase and periplasmic cytochrome assembly in Escherichia coli K-12: CydDC and CcmAB are not required for haem-membrane association
}

\author{
Gregory M. Cook† and Robert K. Poole \\ Author for correspondence: Robert K. Poole. Tel: +44 114222 4447. Fax: +44 1142728697. \\ e-mail:r.poole@sheffield.ac.uk
}

Krebs Institute for Biomolecular Research, Department of Molecular Biology and Biotechnology, The University of Sheffield, Sheffield S10 2TN, UK
The mechanism(s) that bacteria use to transport haem into and across the cytoplasmic membrane to complete the assembly of periplasmic cytochromes is unknown. The authors have tested directly the role(s) of two ATP-binding cassette $(A B C)$ transporters - the cydDC and CCmAB gene products - in Escherichia coli by measuring haem uptake in everted (inside-out) membrane vesicles. If haem is exported to the periplasm in vivo, the same process should result in active accumulation in such everted vesicles. $\left[{ }^{14} \mathrm{C}\right] \mathrm{Haemin}$ (chloride) with bovine serum albumin (BSA) as a carrier protein was accumulated in intact everted membrane vesicles by an energy-independent mechanism. The kinetics of this process were biphasic: rapid uptake/binding was followed by a slower uptake of haem, which was inhibited by a large excess of unlabelled haemin-BSA, but not by BSA. However, accumulated haemin was not chased out of the vesicles by unlabelled haemin-BSA, suggesting specific binding of haemin with the membrane or transport into the lumen of the vesicle. Neither ATP nor a protonmotive force $(\Delta p)$ generated by lactate oxidation was required for haemin binding or subsequent transport, and carbonyl cyanide $\boldsymbol{m}$ chlorophenylhydrazone (CCCP), sodium vanadate and monensin had no effect on haemin transport. The rate of haemin uptake following the initial rapid binding was proportional to the external haemin concentration, suggesting that the uptake process was driven by the haemin concentration gradient across the cell membrane. The kinetics of $\left[{ }^{14} \mathrm{C}\right]$ haemin uptake were similar in wild-type and CydD1 or $\triangle \mathrm{Ccm} A$ mutants, suggesting that the activity of neither the CydDC nor CcmAB transporters is essential for haem export to the periplasm. Cytochrome $d$ levels were unaffected by mutations in trxB (encoding thioredoxin reductase), trxA (thioredoxin), or grx (glutaredoxin), suggesting that the CydDC transporter does not export these components of reducing pathways for cytochrome assembly.

Keywords: cytochrome bd, oxidase, Escherichia coli, haems, membrane transport

\section{INTRODUCTION}

The quinol oxidase, cytochrome $b d$, extensively studied in Escherichia coli and Azotobacter vinelandii, comprises two polypeptide subunits encoded by $c y d A$ and $c y d B$ and three cytochrome haems, $b_{558}, b_{595}$ and $d$ (Gennis \& Stewart, 1996; Poole \& Hill, 1997). In E. coli,

†resent address: Department of Microbiology, Otago School of Abbreviations: $\Delta p$, protonmotive force; $A B C$, ATP-binding cassette; CCCP, carbonyl cyanide $m$-chlorophenylhydrazone. at least two other genes, $c y d C$ and $c y d D$, which constitute an unlinked operon, are necessary for cytochrome $b d$ assembly and function (Georgiou et al., 1987; Poole et al., 1989, 1993, 1994; Delaney et al., 1993; Bebbington \& Williams, 1993). The gene products constitute a membrane transporter in the ABC (ATPbinding-cassette) family (Poole et al., 1993). Two separate integral membrane proteins are envisaged as being necessary for function, as in the bacterial HlyB transporter and the Drosophila white/brown system (Higgins, 1992). The CydDC system appears to be the first prokaryotic example of a heterodimeric $\mathrm{ABC}$ 
transport system in which each polypeptide contains both hydrophobic membrane-spanning and ATP-binding domains (Poole et al., 1993).

Strains having mutations in $c y d D$ also lack periplasmic cytochromes $c$ (Poole et al., 1994; Goldman et al., 1996), and do not assemble cytochrome $b_{562}$ (Goldman et al., 1996). CydD is not required for the synthesis of haem $D$ or the assembly of the CydA and CydB subunits into the membrane (Bebbington \& Williams, 1993). We therefore hypothesized that the CydDC transporter may be required for the export of haem(s) to the periplasm for maturation of soluble cytochromes $c$ and $b$ and perhaps assembly into periplasmically exposed components of cytochrome bd (Poole et al., 1993, 1994). Indeed, the haem-binding site for cytochrome $b_{558}$ (histidine-186) is predicted to be at the periplasmic face, with the implication that haem attachment may occur there (Spinner et al., 1995). Interestingly, Osborne \& Gennis (1999) have reanalysed the probable topology of subunit I of cytochrome $b d$ in several bacteria and conclude that the putative ligand for haem $b_{595}$ is also close to the periplasmic edge of the membrane, and further that the active site of the oxidase comprising this haem and haem $d$ are located near the periplasmic surface. It is not clear whether such a disposition requires haem insertion from outside. The assembly of cytochrome $b o^{\prime}$, the major alternative oxidase, is unaffected by a mutation in cydD1 (G. M. Cook \& R. K. Poole, unpublished data). Some doubt has been cast on the hypothesis that CydDC is a haem transporter by experiments with haem 'reporters' (Goldman et al., 1996): expression of heterologous haemproteins in the periplasm of E. coli results in assembly of the holoprotein (i.e. with haem) even in cydC mutants, suggesting that a pathway for haem export must exist in the absence of the CydDC ABC transporter. An alternative hypothesis for CydDC function is that it is required for maintenance of a redox environment in the periplasm appropriate for haem ligation (Goldman et al., 1996), but again no firm role has been proposed and no substrate for the transporter has been identified.

Efforts to understand periplasmic cytochrome $c$ assembly in E. coli have focused on the eight $\mathrm{Ccm}$ (cytochrome $c$ maturation) proteins (Thöny-Meyer et al., 1994; Grove et al., 1996; Thöny-Meyer, 1997; Throne-Holst et al., 1997; Schulz et al., 1999). One model is that the products of the $c c m A B C$ genes, and perhaps $c c m D$ as well, constitute an $\mathrm{ABC}$ transporter that exports haem to the periplasm, where it is incorporated into cytochrome $c$ apoproteins (ThönyMeyer, 1997). Similar transporters have been proposed in other bacteria: in Paracoccus denitrificans, the $c c m A B C$ genes encode the subunits of an $A B C$ transporter with the composition $(\mathrm{CcmA})_{2}-\mathrm{CcmB}-\mathrm{CcmC}$ (Page et al., 1997). The helABC and helD genes (haem export for ligation) of Rhodobacter capsulatus (Goldman et al., 1997) are also thought to encode an $\mathrm{ABC}$ transporter necessary for cytochrome $c$ assembly. No firm evidence for the transport processes catalysed by such pathways has however been presented. Fur- thermore, since $c c m A B C$ mutants of $P$. denitrificans are able to assemble periplasmic cytochromes $b$, and exogenously added haem fails to restore assembly of periplasmic cytochromes $c$ (Page et al., 1997), this hypothesis appears untenable. Recently, Schultz et al. (1999) have shown in E. coli that CcmA and CcmB (but not $\mathrm{CcmC}$ ) do constitute an $\mathrm{ABC}$ transporter but that it is not essential for cytochrome $c$ maturation. (In this paper, we embrace this finding and refer to the $A B C$ transporter encoded by the $\mathrm{ccm}$ operon in E. coli as $\mathrm{CcmAB}$, not $\mathrm{CcmABC}$.) It is proposed that $\mathrm{CcmC}$ (a transmembrane protein) and $\mathrm{CcmD}$ serve to transfer haem to $\mathrm{CcmE}$, an essential haem chaperone that passes haem to periplasmic apocytochromes. Several lines of evidence suggest that $\mathrm{CcmAB}$ is not a haem transporter (Schulz et al., 1999) but no direct measurements of haem transport have been reported.

Movement of haem into and across lipid bilayers plays a critical role not only in the biogenesis of periplasmic haemproteins in bacteria, but also in that of eukaryotic extramitochondrial haemproteins, such as globins. However, transmembrane movement of haem is likely to be slow (Light \& Olson, 1990), predicting the need for haem transport systems. Nevertheless, despite concerted efforts from several groups and claims for the existence of bacterial haem transporters, no clear candidate has emerged, although putative haem exporters have been found in several bacterial genera (Beckman et al., 1992; Thony-Meyer et al., 1994; Aguilar \& Soberon, 1996; Page et al., 1997). This may be in part a result of technical difficulties in measuring transport kinetics of haem, which self-aggregates in aqueous solutions and interacts non-specifically with cellular components. Some workers have used haem-CO, which is monomeric in dilute aqueous solutions (Light \& Olson, 1990), whilst others have used haem bound to a carrier protein (e.g. Stojiljkovic \& Hantke, 1994). We are unaware of direct attempts to determine rates of haem transport across E. coli isolated cytoplasmic membranes and report such experiments here.

\section{METHODS}

Strains, culture media and growth conditions. E. coli K-12 strains and plasmids used in this study are described in Table 1. Genetic crosses were performed using bacteriophage P1mediated transduction (Miller, 1972). Cells were grown either in Luria broth, initial $\mathrm{pH} 7.0$ (Miller, 1972), or in MOPSbuffered minimal medium with either $40 \mathrm{mM}$ glucose or lactose as sole carbon source (Stewart \& Parales, 1988). The initial $\mathrm{pH}$ of MOPS medium was 7.4. All additions were at the concentrations listed in the text. Kanamycin was used at a final concentration of $50 \mu \mathrm{g} \mathrm{ml}^{-1}$. Agar and other dehydrated media were from Difco or Oxoid. Other components were from Sigma or BDH-Merck.

Culture optical density was generally measured with a PyeUnicam SP6-550 spectrophotometer at $600 \mathrm{~nm}$, using culture samples diluted with medium to bring $\mathrm{OD}_{600}$ to below $0 \cdot 7$ when measured in cuvettes of $1 \mathrm{~cm}$ pathlength. Aerated cultures were grown with shaking (200 r.p.m.). An anaerobic growth atmosphere was generated using a BBL GasPak anaerobic system in an anaerobic jar. 
Table 1. E. coli strains used in this study

\begin{tabular}{|c|c|c|}
\hline Strain & Relevant genotype & Reference or source \\
\hline A179 & $\operatorname{tr} x A 14:$ : kan & Russel et al. (1990) \\
\hline A326 & $\operatorname{tr} x B::$ kan & Russel \& Model (1988) \\
\hline A410 & $\begin{array}{l}\mathrm{K} 38 \Delta \operatorname{trx} A z b i:: \operatorname{Tn} 10 \\
g r x:: \mathrm{kan}\end{array}$ & Russel \& Holmgren (1988) \\
\hline AN2342 & $\mathrm{F}^{-}$; referred to as wild-type & Poole et al. (1989) \\
\hline AN2343 & cydD1 (point mutant) & Poole et al. (1989) \\
\hline EC21 & As MC1061 but $\Delta c c m A$ & Throne-Holst et al. (1997) \\
\hline MC1061 & $\mathrm{F}^{-}$; referred to as wild-type & Throne-Holst et al. (1997) \\
\hline SMB420 & $\operatorname{grx} A \Delta(g a l-g r x)$ & Russel \& Holmgren (1988) \\
\hline
\end{tabular}

Cytochrome $\boldsymbol{d}$ assays. For identification and quantitation of cytochrome $d$, cells were grown in Luria broth (Miller, 1972) to an $\mathrm{OD}_{600}$ of $0 \cdot 9-1 \cdot 0$ (measured after correction for dilution where necessary). Harvested cells were washed in $0 \cdot 1 \mathrm{M}$ potassium phosphate buffer $(\mathrm{pH} 7 \cdot 0)$ and used to record reduced minus oxidized and $\mathrm{CO}$ difference (CO-reduced minus reduced) spectra at room temperature as previously described (Poole et al., 1989). Cytochrome $d$ concentrations were calculated from the former using an absorption coefficient of $18.5 \mathrm{mM}^{-1} \mathrm{~cm}^{-1}$ from $A_{630-650}$ (Kita et al., 1984). The protein content of cell suspensions was assayed by the method of Markwell et al. (1978).

Preparation of everted membrane vesicles. Cells were grown aerobically to the mid-exponential phase of growth, either in minimal MOPS medium supplemented with glucose or lactose or in LB. Defined medium was used only for studies of lactose transport, where variation of carbon source was required (see Results). Cells were harvested by centrifugation and the cell pellet washed with pre-cooled $100 \mathrm{mM}$ potassium phosphate buffer (pH 7•0) containing $10 \mathrm{mM}$ disodium EDTA, and resuspended in the same buffer $(5 \mathrm{ml}$ per litre of original culture). To prepare everted vesicles, the procedure of Thanassi et al. (1997) was used. In brief, cells were disrupted by one passage through a French pressure cell at 5000 p.s.i. (34.5 MPa). Pancreatic DNase was added to $0.1 \mathrm{mg} \mathrm{ml}^{-1}$, and the mixture was kept on ice for $1 \mathrm{~h}$ or until the viscosity decreased significantly. After centrifugation at $27000 \mathrm{~g}$ for $10 \mathrm{~min}$, the vesicles were sedimented from the supernatant suspension by centrifugation at $150000 \mathrm{~g}$ for $1 \mathrm{~h}$. Vesicles were gently resuspended in the same buffer and collected again by centrifuging under the same conditions. They were then resuspended in $100 \mathrm{mM}$ potassium phosphate buffer $(\mathrm{pH} 7 \cdot 2$ ) containing $5 \mathrm{mM} \mathrm{MgCl}_{2}$ to a concentration of $15 \mathrm{mg}$ protein $\mathrm{ml}^{-1}$. Aliquots $(200 \mu \mathrm{l})$ of the vesicles were stored at $-70{ }^{\circ} \mathrm{C}$ after rapid freezing in liquid nitrogen.

$\left[{ }^{14} \mathrm{C}\right]$ Haemin and $\left[{ }^{14} \mathrm{C}\right]$ lactose transport assays. We have adopted the following nomenclature: the term 'haem' is used to describe the chelate complex of $\mathrm{Fe}(\mathrm{II})$ with protoporphyrin IX, the prosthetic group of, for example, cytochrome $b$ or haemoglobin; 'haemin' is the chloride of the Fe(III) form, and 'haematin' is the hydroxide of the $\mathrm{Fe}(\mathrm{III})$ form. $\left[{ }^{14} \mathrm{C}\right] \mathrm{Haemin}$ [approx. $130 \mathrm{mCi} \mathrm{mmol}^{-1}\left(4810 \mathrm{MBq} \mathrm{mmol}^{-1}\right)$ ] was purchased from Professor Stan Brown, University of Leeds Innovations Ltd (Woodhouse Lane, Leeds LS2 3AR, UK). Haemin transport assays were based on previously established methods (Stojiljkovic \& Hantke, 1994; Tompkins et al., 1997). $\left[{ }^{14} \mathrm{C}\right]$ Haemin $(1 \mu \mathrm{Ci} ; 37 \mathrm{kBq})$ was solubilized in a drop of $0 \cdot 1 \mathrm{M} \mathrm{NaOH}$ and diluted with $50 \mathrm{mM}$ potassium phosphate buffer $(\mathrm{pH} 7 \cdot 2)$ containing bovine serum albumin
(BSA; $10 \mathrm{mg} \mathrm{ml}^{-1}$ ) as a carrier for haemin to avoid polymerization, self-aggregation, and non-specific interaction with cellular components. $\left[{ }^{14} \mathrm{C}\right]$ Lactose $\left(57 \mathrm{mCi} \mathrm{mmol}^{-1}\right.$; $2109 \mathrm{MBq} \mathrm{mmol}^{-1}$; Amersham) was added to achieve a final concentration of $400 \mu \mathrm{M}$ in the transport assay. Everted vesicles were thawed slowly on ice and diluted to a protein concentration of $0.5-1 \cdot 0 \mathrm{mg} \mathrm{ml}^{-1}$ in $50 \mathrm{mM}$ potassium phosphate buffer $\left(\mathrm{pH} \mathrm{7 \cdot 2)}\right.$ containing $5 \mathrm{mM} \mathrm{MgCl}_{2}$. Vesicles were added to glass tubes containing $200 \mu \mathrm{l}$ of the same pre-warmed phosphate buffer and pre-incubated for $15 \mathrm{~min}$ without shaking in a water bath at $30^{\circ} \mathrm{C}$. To initiate transport, radiolabelled $\left[{ }^{14} \mathrm{C}\right]$ haemin or $\left[{ }^{14} \mathrm{C}\right]$ lactose was added to achieve final concentrations of $5.7 \mu \mathrm{M}$ or $400 \mu \mathrm{M}$, respectively. Vesicles were energized for $15 \mathrm{~min}$ prior to $\left[{ }^{14} \mathrm{C}\right]$ haemin-BSA or $\left[{ }^{14} \mathrm{C}\right]$ lactose addition with either $10 \mathrm{mM}$ D-lactate or ATP (2-5 mM). Vesicles were de-energized with either carbonyl cyanide $m$-chlorophenylhydrazone (CCCP; $50 \mu \mathrm{M})$ to collapse the proton gradient $(\Delta \mathrm{p})$, monensin $(100 \mu \mathrm{M})$ to collapse a sodium gradient, or sodium vanadate $(100 \mu \mathrm{M})$, a specific inhibitor of ATP-driven transport systems (Pressman, 1976). After $0-20 \mathrm{~min}$, transport was terminated by the addition of ice-cold $\mathrm{LiCl}(2 \mathrm{ml}, 100 \mathrm{mM})$ and rapid filtration $(0.45 \mu \mathrm{m}$ pore size cellulose-nitrate filter). The filter was washed twice with $2.0 \mathrm{ml}$ of the $\mathrm{LiCl}$ solution, dried for $20 \mathrm{~min}$ at $105^{\circ} \mathrm{C}$, and radioactivity measured by liquid scintillation counting. To minimize non-specific binding of $\left[{ }^{14} \mathrm{C}\right]$ haemin-BSA to filters, the filters were pre-soaked in $100 \mathrm{mM} \mathrm{LiCl}$ containing BSA $\left(10 \mathrm{mg} \mathrm{ml}^{-1}\right)$.

\section{RESULTS}

\section{$\left[{ }^{14} \mathrm{C}\right]$ Haemin-BSA and $\left[{ }^{14} \mathrm{C}\right]$ lactose transport in everted membrane vesicles from wild-type cells}

The inwardly directed transport of $\left[{ }^{14} \mathrm{C}\right]$ haemin-BSA by everted membrane vesicles was measured. Transport under these conditions would simulate the export of haem from the cytoplasm (outside of vesicle) to the periplasm (lumen of vesicle). First, to demonstrate that the everted vesicle procedure used here was effective for the strains in this study, we tested the ability of vesicles to accumulate $\left[{ }^{14} \mathrm{C}\right]$ lactose in response to an energized membrane. Lactose can be transported by both rightside-out and everted vesicles, provided that an energy source such as sodium lactate is supplied to generate a protonmotive force $(\Delta \mathrm{p})$. Everted vesicles prepared from cells grown in MOPS minimal medium supplemented with glucose had a low rate of lactose uptake 

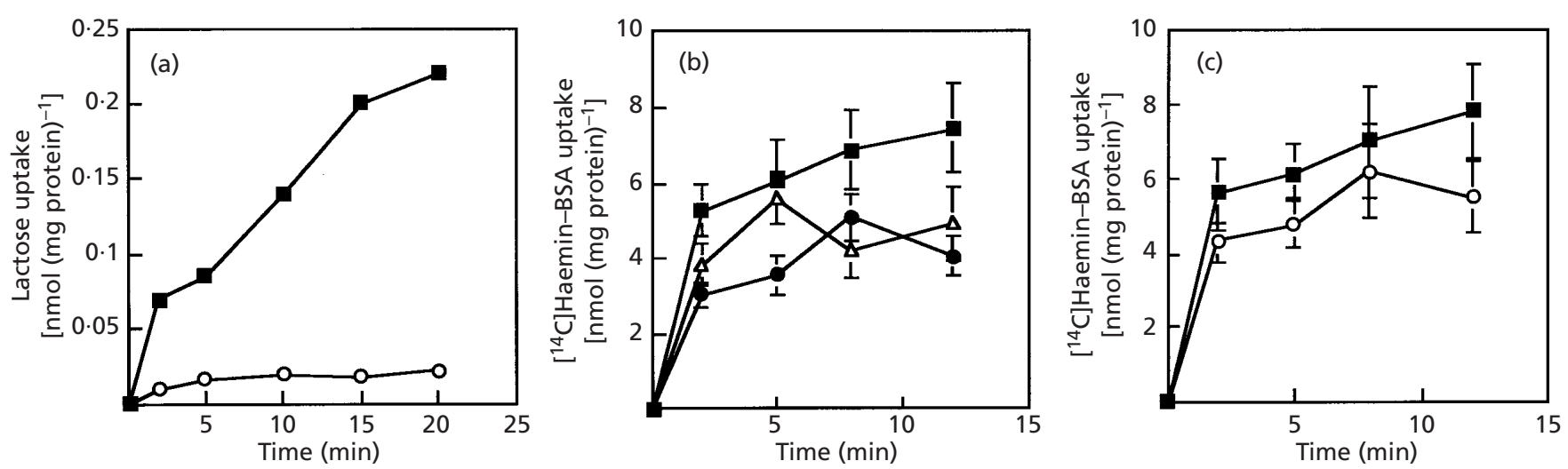

Fig. 1. Comparison of uptake of $\left[{ }^{14} \mathrm{C}\right]$ lactose and $\left[{ }^{14} \mathrm{C}\right]$ haemin-BSA by everted membrane vesicles from wild-type and cydD mutant strains of E. coli. In (a), vesicles were prepared from strain AN2342 (wild-type) grown in MOPS minimal medium with lactose as sole carbon source. Sodium lactate $(20 \mathrm{mM}$ final concentration) was added 15 min prior to addition of $\left[{ }^{14} \mathrm{C}\right]$ lactose $(400 \mu \mathrm{M}$ final concentration) at time zero $(\boldsymbol{\square})$, but not in the control $(\bigcirc)$. Results are typical of several experiments. In (b) and (c), everted vesicles were prepared from cells grown aerobically in LB medium. In (b), ATP $(0,5 \mathrm{mM})$ or sodium lactate $(\triangle, 20 \mathrm{mM})$ was added to vesicles from the wild-type strain (AN2342), $15 \mathrm{~min}$ prior to addition of $\left[{ }^{14} \mathrm{C}\right]$ haemin-BSA $(5 \cdot 7 \mu \mathrm{M}$ final haemin concentration). The control ( $\boldsymbol{\square})$ contained neither ATP nor sodium lactate. In (c), $\left[{ }^{14} \mathrm{C}\right]$ haemin-BSA uptake by vesicles from strain AN2343 (cydD1, O) and AN2342 (wild-type, 口) is compared; no ATP or sodium lactate was added. Values shown are means \pm SD bars.

$\left[<1.5 \times 10^{-3} \mathrm{nmol} \mathrm{min}^{-1}(\mathrm{mg} \text { protein })^{-1}\right.$; not shown $]$ and this rate (determined over the first $60 \mathrm{~s}$ ) was increased 25-fold [to $0.04 \mathrm{nmol} \mathrm{min}^{-1}$ (mg protein ${ }^{-1}$ )] if cells were grown with lactose as the sole carbon and energy source in minimal medium. Significant $\left[{ }^{14} \mathrm{C}\right]$ lactose uptake occurred only if sodium lactate was added as an energy source in the transport assay (Fig. 1a). Lactose-grown cells were also used in preliminary experiments to measure accumulation of $\left[{ }^{14} \mathrm{C}\right]$ haemin, with similar results to those below. These results demonstrate that the everted vesicles used are capable of energization by sodium lactate and actively accumulate $\left[{ }^{14} \mathrm{C}\right]$ lactose or $\left[{ }^{14} \mathrm{C}\right]$ haemin with time. ATP $(5 \mathrm{mM})$ addition was also able to energize lactose transport (data not shown). This accumulation was abolished by the addition of CCCP $(50 \mu \mathrm{M}$ final concentration) (data not shown), demonstrating that the vesicles are intact and that lactose transport is dependent on $\Delta \mathrm{p}$.

To test the ability of everted vesicles to accumulate $\left[{ }^{14} \mathrm{C}\right]$ haemin, BSA was used as a carrier protein for $\left[{ }^{14} \mathrm{C}\right]$ haemin. BSA was included at concentrations exceeding that of total haemin to prevent non-specific binding and self aggregation of the haemin (Stojiljkovic \& Hantke, 1994; Tompkins et al., 1997). The haeminalbumin dissociation constant is $10^{-8} \mathrm{M}$ and therefore haemin is bound with high affinity by this protein (Beaven et al., 1974). When $\left[{ }^{14} \mathrm{C}\right]$ haemin-BSA $(5 \cdot 7 \mu \mathrm{M}$ final concentration) was added to vesicles from wildtype strain AN2342, even in the absence of an energy source, the kinetics of $\left[{ }^{14} \mathrm{C}\right]$ haemin-BSA uptake were biphasic (Fig. 1b). Substantial association of $\left[{ }^{14} \mathrm{C}\right]$ haemin-BSA with the vesicles occurred within 2 min of haemin addition (Fig. 1b) and similar counts were obtained after incubation for only $5 \mathrm{~s}$ (not shown). The rapidity of the reaction and its ATP independence strongly suggest that this phase represents binding of the haem to the lipid bilayer as reported previously for liposomes (Rose et al., 1985). After this initial rapid binding, there was further uptake of $\left[{ }^{14} \mathrm{C}\right]$ haemin-BSA, which steadily increased with further incubation. The rate of this uptake calculated between 2 and 12 min after haemin addition was $0.08 \mathrm{nmol} \min ^{-1}$ (mg protein $)^{-1}$. At $12 \mathrm{~min}$, the amount of $\left[{ }^{14} \mathrm{C}\right]$ haemin-BSA that had been taken up represented less than $20 \%$ of the total radioactive concentration of $\left[{ }^{14} \mathrm{C}\right]$ haemin, indicating that haemin uptake was still occurring and that the system was not fully saturated due to all the $\left[{ }^{14} \mathrm{C}\right]$ haemin-BSA having been bound.

Because CydDC is an ABC transporter presumed to be energized by ATP, ATP $(5 \mathrm{mM})$ was added to the transport assay $10 \mathrm{~min}$ before $\left[{ }^{14} \mathrm{C}\right]$ haemin-BSA. When either ATP or sodium lactate was added to the membrane vesicles prior to $\left[{ }^{14} \mathrm{C}\right]$ haemin-BSA addition, both the initial $\left[{ }^{14} \mathrm{C}\right]$ haemin-BSA binding and the subsequent transport occurred at rates (again determined between 2 and $12 \mathrm{~min}$ ) that did not differ significantly from that seen where neither ATP nor lactate had been added (Fig. $1 \mathrm{~b}$, Table 2). It is probable that the differences between the three uptake experiments shown in Fig. 1(b) and below (Fig. 3) are due to the experimental difficulties of working with solutions of such a hydrophobic substrate, and are not due to major differences in the proportion of vesicles that are everted (see Discussion). We conclude that the uptake of $\left[{ }^{14} \mathrm{C}\right]$ haemin-BSA is not dependent on an externally provided energy source. Furthermore, none of sodium vanadate $(100 \mu \mathrm{M})$, monensin $(100 \mu \mathrm{M})$ or CCCP $(50 \mu \mathrm{M})$ had any significant effect on the rate of $\left[{ }^{14} \mathrm{C}\right]$ haemin-BSA uptake by wild-type cells (results not shown), suggesting that an energized membrane is not required for haemin uptake and that ATP-driven transporter activity does not play a major role in haemin transport in these vesicles. 
Table 2. Effect of external energy sources and metabolic inhibitors on $\left[{ }^{14} \mathrm{C}\right]$ haemin-BSA uptake by strains of $E$. coli

$\left[{ }^{14} \mathrm{C}\right]$ Haemin-BSA was added to a final concentration of $5.7 \mu \mathrm{M}$. ATP $(5 \mathrm{mM}$ final concentration) or lactate $(20 \mathrm{mM}$ final concentration) was added, except in the controls, $15 \mathrm{~min}$ prior to $\left[{ }^{14} \mathrm{C}\right]$ haemin-BSA addition. The rates reported were determined from $2 \mathrm{~min}$ to $12 \mathrm{~min}$. The data are means of three independent determinations; errors associated with these means are demonstrated by Figs 1 and 3 .

\begin{tabular}{|c|c|c|c|}
\hline \multirow[t]{2}{*}{ Strain, genotype } & \multicolumn{3}{|c|}{$\begin{array}{l}\text { Rate of haemin transport } \\
{\left[\text { nmol } \min ^{-1}(\mathrm{mg} \text { protein })^{-1}\right]}\end{array}$} \\
\hline & Control & $+\mathrm{ATP}$ & + Lactate \\
\hline AN2342, wild-type & $0 \cdot 09$ & $0 \cdot 10$ & $0 \cdot 11$ \\
\hline $\mathrm{AN} 2343, c y d D 1$ & $0 \cdot 06$ & $0 \cdot 08$ & $0 \cdot 08$ \\
\hline MC1061, wild-type & $0 \cdot 15$ & $0 \cdot 16$ & $0 \cdot 13$ \\
\hline $\mathrm{EC} 21, \Delta c c m A$ & $0 \cdot 17$ & $0 \cdot 18$ & $0 \cdot 16$ \\
\hline
\end{tabular}

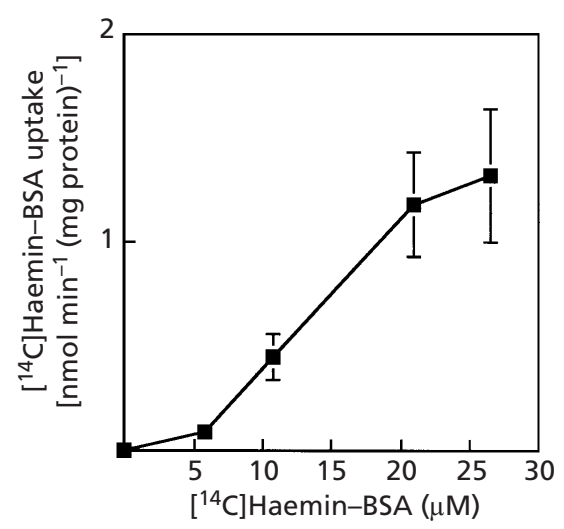

Fig. 2. Dependence of the rate of $\left[{ }^{14} \mathrm{C}\right]$ haemin uptake by everted membrane vesicles of AN2342 on haemin-BSA concentration. The rates of haemin uptake shown were determined from $2 \mathrm{~min}$ to $12 \mathrm{~min}$ after addition of $\left[{ }^{14} \mathrm{C}\right]$ haemin-BSA. No ATP or sodium lactate was used in these assays. Values shown are means \pm SD bars.

Because $\left[{ }^{14} \mathrm{C}\right]$ haemin-BSA uptake did not appear to be dependent on an energized membrane, the driving force for $\left[{ }^{14} \mathrm{C}\right]$ haemin-BSA was studied. When the external concentration of $\left[{ }^{14} \mathrm{C}\right]$ haemin-BSA was varied from $5.7 \mu \mathrm{M}$ to $28 \mu \mathrm{M}$, the rate of $\left[{ }^{14} \mathrm{C}\right]$ haemin-BSA uptake determined between 2 and $12 \mathrm{~min}$ was proportional to the external haemin concentration over the range from about 5 to $20 \mu \mathrm{M}$ (Fig. 2), indicative of a diffusion type transport mechanism. This mechanism does not rule out the possibility that carrier proteins embedded in the membrane facilitate transmembrane movement.

It is technically difficult to determine how much of the $\left[{ }^{14} \mathrm{C}\right]$ haemin-BSA that was taken up by the everted membrane vesicles is inside the vesicles and how much resides at the outer leaflet of the inside-out membrane vesicle. To determine if this $\left[{ }^{14} \mathrm{C}\right]$ haemin-BSA was specifically bound, the vesicle-bound $\left[{ }^{14} \mathrm{C}\right]$ haemin-BSA was chased with a large excess of unlabelled haeminBSA. In these experiments, vesicles were pre-incubated with $\left[{ }^{14} \mathrm{C}\right]$ haemin-BSA for $10 \mathrm{~min}$ and then a 150 -fold excess of non-radioactive haemin-BSA was added to the transport assay. The rate of $\left[{ }^{14} \mathrm{C}\right]$ haemin-BSA uptake was determined over a further $10 \mathrm{~min}$. When unlabelled haemin-BSA was added to wild-type membrane vesicles that had been accumulating $\left[{ }^{14} \mathrm{C}\right]$ haemin-BSA for $10 \mathrm{~min}$, there was no further uptake of $\left[{ }^{14} \mathrm{C}\right]$ haeminBSA, presumably because the binding sites and accumulation within the vesicles were saturated (Fig. 3a). That the unlabelled haemin-BSA did not displace a significant fraction of the label suggests that $\left[{ }^{14} \mathrm{C}\right]$ haemin-BSA was either bound specifically to the membrane, probably associated with protein, or had accumulated in the lumen of the vesicle.

\section{$\left[{ }^{14} \mathrm{C}\right]$ Haemin-BSA transport in everted membrane vesicles from $A B C$ transporter mutants}

The ATP-independence of the haem movements described above strongly suggests that the activities of ABC-type transporters, such as CydDC or CcmAB, do not contribute significantly. This was confirmed by experiments with vesicles prepared from the cydD1 mutant AN2343, which revealed similar patterns of $\left[{ }^{14} \mathrm{C}\right]$ haemin-BSA uptake as in the isogenic wild-type strain (Fig. 1c). The rate of $\left[{ }^{14} \mathrm{C}\right]$ haemin-BSA uptake as determined between 2 and $12 \mathrm{~min}$ was $0.06 \mathrm{nmol} \mathrm{min}{ }^{-1}$ $(\mathrm{mg} \text { protein })^{-1}$ (Table 2$)$. As observed for the wild-type strain, unlabelled haemin-BSA did not displace a significant fraction of the label from vesicles prepared from the $c y d D 1$ mutant (Fig. $3 \mathrm{~b}$ ).

To test the role of the $\mathrm{CcmAB}$ proteins in haemin transport, everted vesicles were prepared from cells grown anaerobically on glycerol and nitrate, conditions required for the induction of the $c c m A B$ genes. Everted vesicles from either MC1061 (wild-type) or EC21 $(\Delta c c m A)$ accumulated $\left[{ }^{14} \mathrm{C}\right]$ haemin-BSA with time and there was little difference between the strains in terms of the rate of $\left[{ }^{14} \mathrm{C}\right]$ haemin-BSA uptake as calculated between 2 and 12 min (Fig. 3c, Table 2). The uptake was biphasic, and bound $\left[{ }^{14} \mathrm{C}\right]$ haemin-BSA could not be chased in either strain and was not dependent on an exogenous energy source (Table 2).

\section{Effect of the reducing environment on cytochrome bd assembly}

Goldman et al. (1996) reported that $c y d C$ mutants have a more oxidized periplasm than that of wild-type cells and $c y d A B$ mutants. These results are consistent with the CydDC transporter exporting a reductant to the periplasm that is required either for haem ligation and/or to ensure that the redox environment of the periplasm is appropriate for haem ligation. To test this hypothesis, a number of reducing pathways in E. coli were tested for their effect on cytochrome $d$ levels. Wildtype cells contained approximately $0.04 \mathrm{nmol}$ haem $d$ $(\mathrm{mg} \text { protein })^{-1}$ as measured in reduced minus oxidized and $\mathrm{CO}$ difference spectra (not shown). In contrast, 

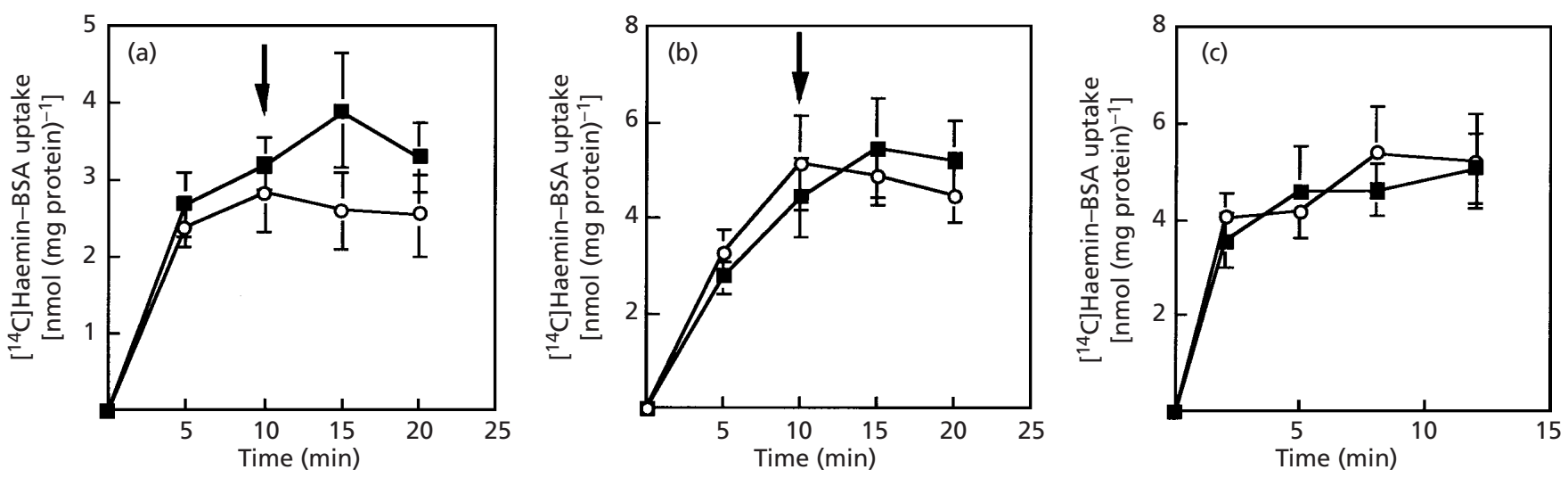

Fig. 3. $\left[{ }^{14} \mathrm{C}\right]$ Haemin transport by everted vesicles from wild-type cells and $A B C$ transporter mutants and the effects of chasing with unlabelled haemin. For strains AN2342 (wild-type) (a) and AN2343 (cydD1) (b), everted vesicles were prepared from cells grown aerobically in LB medium, and transport was assayed as described in Fig. 1. An excess (150fold) of unlabelled haemin-BSA was added at $10 \mathrm{~min}$ (indicated by the arrows) to chase non-specifically bound haemin $(\bigcirc)$. In controls ( $\boldsymbol{\square})$, no excess unlabelled haemin was added. Panel (c) shows $\left[{ }^{14} \mathrm{C}\right]$ haemin-BSA uptake by everted membrane vesicles prepared from strains MC1061 (wild-type, $\square$ ) and EC21 ( $\triangle c c m A, O)$ grown anaerobically on glycerol and nitrate. In all experiments, no ATP or sodium lactate was added. Values shown are means \pm SD bars.

cytochrome $d$ levels in an isogenic cydD1 mutant were undetectable. Mutations in the upstream gene $\operatorname{tr} x B$ did not reduce the level of cytochrome $d$ significantly compared to the wild-type, confirming previous results (Poole et al., 1994). Furthermore, mutations in grxA (glutaredoxin), $\operatorname{tr} x A$ (thioredoxin), or both alleles, $(\operatorname{gr} x A \operatorname{tr} x A)$ did not cause a loss of cytochrome $d$ (not shown).

\section{DISCUSSION}

It is well established that haem rapidly associates with lipid bilayers. The aromatic portion of haem is thought to intercalate between the acyl chains of neighbouring lecithins in liposome model systems and the haem propionates lie in the polar region of the bilayer (Cannon et al., 1984). Nevertheless, the outer membranes of Gram-negative bacteria are considered impermeable to haem (McConville \& Charles, 1979). This has led to the characterization of haem-utilization systems from other bacteria by complementation of E. coli hemA mutants (Henderson \& Payne, 1994; Stojiljkovic \& Hantke, 1992; Stojiljkovic et al., 1996; Torres \& Payne, 1997).

However, there is conflicting evidence regarding the ability of haemin to penetrate the cytoplasmic membrane and the requirement for specific haem transporters, whether for inward or outward movement (with reference to the cell) in this process. First, respiration-deficient membrane vesicles from a hem $A$ mutant of E. coli, which cannot synthesize haem, can be reconstituted in vitro by adding haematin and ATP (Haddock \& Schairer, 1973). If cytoplasmic membranes are intrinsically impermeable to haem, this result implies either that all haemproteins required for respiration are exposed to the outer faces of the membrane vesicles, or that haem transport is driven by ATP. Respiration is not reconstituted, however, by adding haematin to cells during growth (Haddock \& Schairer, 1973), presumably because of the requirement for outer-membrane haem receptor and transport systems in E. coli (Stojiljkovic \& Hantke, 1992). Stojiljkovic \& Hantke (1992) expressed the Yersinia enterocolitica haemin receptor HemR in E. coli $\mathrm{K}-12$, thus conferring the ability to use haemin as a porphyrin source. Additional gene products appear necessary for using haemin as an iron source, since $Y$. enterocolitica mutants defective in hemU and hemV (encoding a putative haem-specific permease and ATPase, respectively) are severely impaired in haemin utilization, yet still show weak growth stimulation by haemin (Stojiljkovic \& Hantke, 1994). This suggests leakage of haemin through the cytoplasmic membrane. Furthermore, Torres \& Payne (1997) have demonstrated that introduction of the gene for an outer-membrane protein is sufficient to confer haem utilization in E. coli $\mathrm{K}-12$, and growth in vivo of pathogenic E. coli strains is stimulated by haemin or haemoglobin, perhaps again indicating the presence of a cytoplasmic membrane transporter for haem (Stojiljkovic \& Hantke, 1994) or perhaps that only the outer membrane presents a significant barrier to uptake to the cytoplasm. Nevertheless, it is tacitly assumed that E. coli has a mechanism(s) for haem translocation from the cytoplasm to the outer face of the cytoplasmic membrane, where it is required for periplasmic cytochrome assembly (Beckman et al., 1992; Goldman et al., 1998; Thony-Meyer et al., 1994; Thony-Meyer, 1997). Such a mechanism(s) has so far remained unidentified.

The present study has used everted vesicles prepared after cell disruption in the French pressure cell. It is widely recognized that this procedure results in a population of vesicles that is predominantly inverted with respect to the in vivo orientation. We consider it unlikely that the small variations seen between experiments (as in Figs 1 and 3) are due to variation in the proportion of everted vesicles, since specific transport 


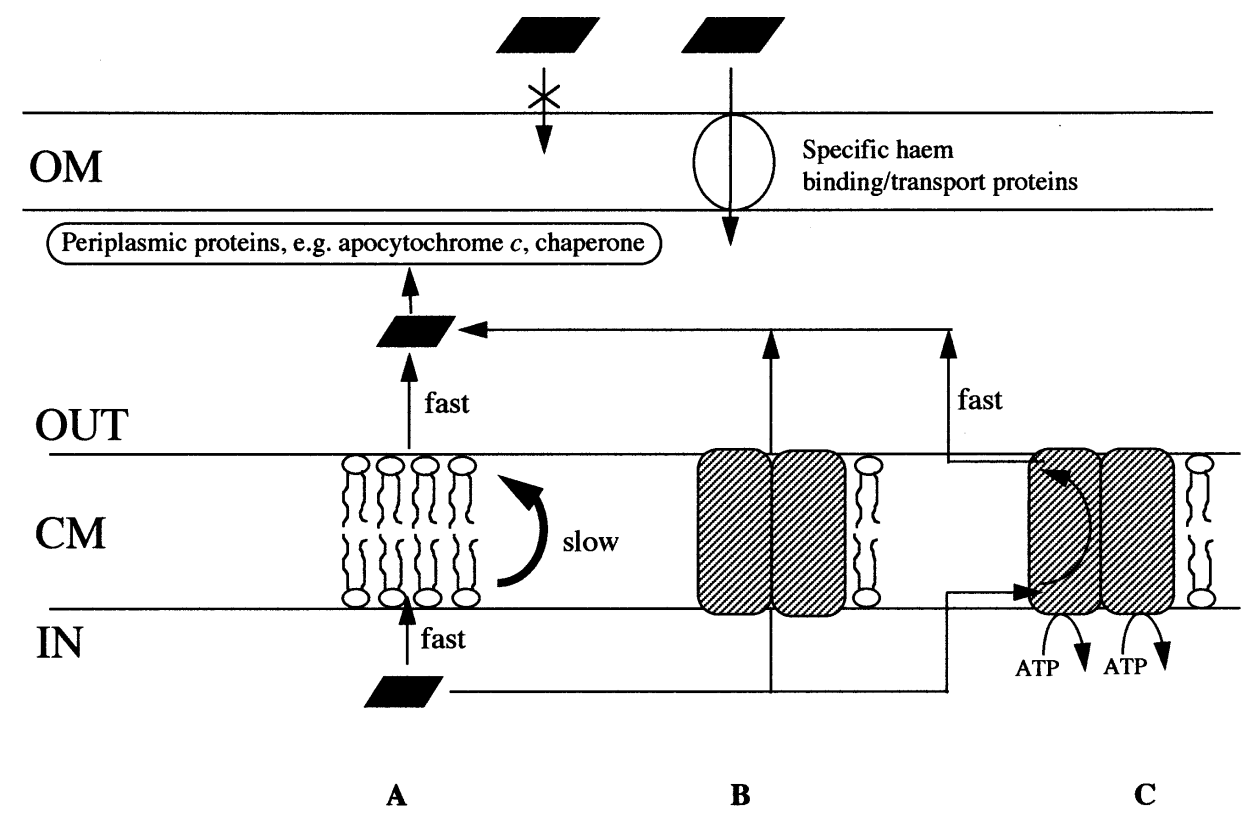

Fig. 4. Possible pathways for haem reaction with, and transport through, the cytoplasmic membrane of $E$. coli. Haem synthesized in the cytoplasm (IN) associates rapidly with the inner leaflet of the cytoplasmic membrane, largely through hydrophobic interactions. The anticipated, relatively slow (see text) flipping of haem to the outer leaflet is shown in A. Alternatively (B), haem may be transported through the membrane via a pore formed by a specific transporter. Finally (C), haem may interact within the bilayer with a carrier, such as an ABC-type exporter, which acts as a 'flippase', speeding up, in an ATP-dependent fashion, the movement of haem to the outer leaflet or directly into the periplasm (OUT). Dissociation of haem from the outer leaflet is proposed to be facilitated by the presence of haem-binding protein(s) such as the haem chaperone CcmE (not shown). Other proteins may be involved in initial haem capture or the haem may be involved directly in insertion into apohaemproteins like cytochrome $c$ or $b_{562}$, or perhaps into the periplasmically exposed regions of the cytochrome bd quinol oxidase (not shown). The outer membrane (OM) is portrayed as being impermeable to haem, and thus requiring haem transport proteins (not detailed).

activity has been shown by others to be insensitive to experimental variables, specifically French cell pressure, for example, between 4000 and 14000 p.s.i. The procedure of Thanassi et al. (1997) used here gives vesicles that exhibit negligible uptake of proline (which is transported inwards in vivo), which is stimulated 60fold when vesicles are prepared by lysosyme-EDTA treatment (McMurry et al., 1980). Other criteria for the everted nature of vesicles isolated after French press disruption include high rates of uptake of $\mathrm{Ca}^{2+}$ (which is exported by intact cells), accessibility of substrates to enzymes whose activity is normally cryptic, the direction of respiration- and ATPase-driven $\mathrm{H}^{+}$translocation, exposure of inaccessible antigenic determinants, and morphology (Rosen \& Tsuchiya, 1979). On these bases it seems highly probable that the haem-membrane interactions described here are with everted vesicles.

We found that interaction of haem with the membrane does not require ATP, an oxidizable substrate, or $\Delta \mathrm{p}$. $\left[{ }^{14} \mathrm{C}\right]$ Haemin-BSA uptake appears to be a biphasic process. The first rapid phase is probably haem-lipid association; the second slower phase is driven by the concentration gradient of haemin across the cell membrane and probably represents haem movement across the bilayer, possibly resulting in ultimate dissociation from the 'inner' face of the membrane (Fig. 4). The lack of saturation kinetics suggests either that the process is not catalysed by specific transport proteins or that higher concentrations of haemin are required for saturation. These results agree with those obtained for haem-CO and unilamellar lipid vesicles (Light \& Olson, 1990): 'transmembrane movement is slow and distinct from the initial binding process'. Possible involvement of the $c y d D C$ and $c c m A B$ gene products in haemin transport could not be demonstrated, the rates of haemin uptake being comparable in wild-type and mutant strains. Thus, the CydDC and CcmAB transporters do not seem to be necessary for haem transport, but our experiments do not rule out the possibility that such proteins accelerate haem transport in vivo or the existence of other haem-binding membrane components. The lack of involvement of CydDC in haem transport might seem to support the work of Goldman et al. (1996), who expressed various haem apoproteins in the E. coli periplasm and showed that mutations in $c y d C$ did not prevent periplasmic holoprotein assembly, even in the absence of exogenous haemin. However, the experiments of Light \& Olson (1990) clearly demonstrate the possibility of haem movement into and out of the bilayer in the absence of transport proteins; dissociation from the bilayer is readily demonstrated when liposomes with embedded haem are mixed with apomyoglobin. Thus the experiments of Goldman et al. 
(1996), which utilized artefactually high periplasmic concentrations of apoproteins, may have provided a 'trap' for haem dissociating outwards from the bilayer into the periplasm. The mechanism for such haem movement in E. coli is becoming clearer. CcmE is a protein $\mathrm{N}$-terminally anchored to the cytoplasmic membrane, which accumulates in a haem-bound form in $c c m F$ mutants defective in cytochrome $c$ assembly (Reid et al., 1998). The haem is bound covalently by a histidine residue and is released in the presence of apocytochrome $c$ and other Ccm proteins needed for assembly (Schulz et al., 1998). Schulz et al. (1999) have shown that only $\mathrm{CcmC}$ is absolutely required for the charging of $\mathrm{CcmE}$ with haem, at least when CcmC is highly expressed. It could not be excluded from those experiments, however, that haem translocation normally occurs via the $\mathrm{CcmAB}$ transporter, only that high abundance of $\mathrm{CcmC}$ allows haem to cross the membrane in the absence of CcmAB. Perhaps the strong haem binding of $\mathrm{CcmC}$ (evidenced by the persistence of haem in SDS gels) could 'pull' or extract haem from the lipid bilayer, as demonstrated for the reaction of apomyoglobin with liposomes (Light $\&$ Olson, 1990).

In this work, radioactive haemin-BSA uptake was inhibited by the addition of an excess of non-radioactive haemin-BSA, but not by BSA alone. Significantly, the bound haemin was not chased by unlabelled haemin. Like Stojiljkovic \& Hantke (1994), we interpret this as indicating specific binding, presumably to haem-binding components of the membrane that have a greater affinity for haemin than does BSA. The identity of these components is presently unknown, but haem-starved Prevotella intermedia cells express approximately 4000 haem binding sites per cell and a haem dissociation constant of $1 \times 10^{-9}$ (Tompkins et al., 1997). Other haem-binding proteins also have a high affinity for binding haem. For example the haem-haemopexin complex has a dissociation constant of $10^{-12} \mathrm{M}$ (Hrkal et al., 1974) and haptoglobin has an extremely high affinity for binding haemoglobin $\left(K_{\mathrm{d}}\right.$ of $\left.<10^{-15} \mathrm{M}\right)$ (Hwang \& Greer, 1980).

Phospholipid membranes have a high affinity for haem, and the interaction of phospholipid with haemin, which can be considered 'an aromatic, soap-like molecule' (Rose et al., 1985), has a major hydrophobic component. It is therefore pertinent to compare possible mechanisms of haem transport with what is known about hydrophobic drugs. These have also been shown to be taken up by a biphasic process (see Bolhuis et al., 1997 for a review). Normally this is observed as a fast entry into the outer leaflet of the membrane followed by a slower movement across the bilayer to the inner leaflet of the membrane (Bolhuis et al., 1997). The ability of amphiphilic substrates to partition in the inner leaflet of the membrane is a prerequisite for recognition by multidrugresistant transporters which might function as a hydrophobic 'vacuum cleaner' to remove drugs from the inner leaflet and extrude them from the membrane. There is a direct relationship between the amount of hydrophobic drug associated with the cytoplasmic leaflet of the lipid bilayer and the rate of transport, as observed for drug extrusion by the lactococcal multidrug transporter LmrP (Bolhuis et al., 1997). According to the 'flippase' model (Higgins \& Gottesman, 1992), the function of the ABC transporter might be to pump substrate (perhaps haem ?) from the inner to the outer leaflet (Fig. 4), from where the haem may diffuse to the periplasm, haem chaperone or membrane-associated apoprotein. In our experiments, inability to chase labelled haemin may reflect tight binding to the CydDC subunits even though they are incapable of active translocation. The idea of flipping is not new, and this term was used by Rose et al. (1985) in the context of haem transport. Interestingly, though, the experiments of Light \& Olson (1990) with unilamellar lipid vesicles reveal a second slow phase in both the association and dissociation directions that might equate with the transmembrane movement role envisaged for $A B C$ transporters. It is important to note that the present results do not rule out energizationdependent haem translocation from an aqueous phase on one side of the membrane to the aqueous phase on the other. Our results show only that haemin (proffered as a BSA complex) is bound to the membrane, and rendered incapable of being chased, independently of membrane energization or the involvement of CydDC or CcmAB. It is feasible, for example that, in vivo, haem binds to the inner leaflet of the cytoplasmic membrane bilayer and may cross to the outer leaflet, and only then might its passage into the periplasm (or the interior of a vesicle) require the ATPase activity of the transporter.

Could haem export to the periplasm proceed without a specific transporter? Although the transmembrane movement of haem-CO in liposomes having long unsaturated acyl chains is very slow (the release phase having a rate constant of about $0.001 \mathrm{~s}^{-1}$; Light \& Olson, 1990), such rate constants may underestimate the in vivo rates for natural haem substrates. The rate may be raised further by protein-induced discontinuities in apolar regions of the membrane similar to that seen in vitro at temperatures near the phase-transition temperature. Finally, perhaps even a half-time of $10 \mathrm{~min}$ for haem flipping as estimated for egg lecithin liposomes might be sufficient for haem assembly and function in the periplasm.

Despite results from many laboratories, the substrates for the transporters encoded by both the $c y d D C$ and $c c m A B$ gene products are unknown. Recent work from Ferguson and co-workers has suggested that the putative CcmABC haem transporter in P. denitrificans does not transport either haem or $c$-type apocytochromes and suggests a low-molecular-mass thiol or oxidized thiol as substrate (Page et al., 1997). However, cysteine, glutathione or 2-mercaptoethanesulfonic acid could not complement a $\triangle c c m A$ mutation in E. coli (Schulz et al., 1998). Similar proposals for the nature of the transported substrate have been put forward by Poole et al. (1994) and Schulz et al. (1999). Essentially, the substrate is considered to be a reductant that keeps haem and/or apoprotein cysteine residues in the periplasm reduced for haem ligation, despite the oxidizing environment of 
the periplasm. Disulfide bond formation plays a key role in protein folding in the periplasm of Gram-negative bacteria (Raina \& Missiakis, 1997). It is notable then that: (a) the gene upstream of the $c y d D C$ operon is $\operatorname{tr} x B$, encoding thioredoxin reductase (Russel \& Model, 1988), and (b) in many cases, genes encoding an $\mathrm{ABC}$ exporter are adjacent to the gene encoding the transported product (Salmond \& Reeves, 1993). In the cytoplasm, a reducing balance is maintained using three glutaredoxins (products of $g r x A, \operatorname{gr} x B$ and $g r x C$ ) as well as the thioredoxin $(\operatorname{tr} x A / \operatorname{tr} x C) /$ thioredoxin reductase $(\operatorname{tr} x B)$ system (for a review, see Aslund \& Beckwith, 1999). Furthermore, Goldman et al. (1996) have reported that $c y d C$ mutants have a more oxidized periplasm than do wild-type and $c y d A B$ mutants. These results are consistent with the CydDC proteins exporting a reductant to the periplasm that is required either for haem ligation and/or to ensure a redox environment of the periplasm appropriate for haem ligation. However, the present results show that none of $\operatorname{tr} x B, \operatorname{tr} x A$ or $g r x A$ is required for cytochrome $b d$ assembly, although $\operatorname{tr} x A$ function is needed for the transfer of electrons from the cytoplasm to periplasmic DsbC for cytochrome $c$ assembly (Reid et al., 1998).

\section{ACKNOWLEDGEMENTS}

This work and G. M.C. were supported by BBSRC Research Grant CO2063 (awarded to R.K.P.). We thank Linda ThönyMeyer and Lars Hederstedt for supplying bacterial strains.

\section{REFERENCES}

Aguilar, G. R. \& Soberon, M. (1996). Cloning and sequence analysis of the Rhizobium etli ccmA and $c \mathrm{cmB}$ genes involved in c-type cytochrome biogenesis. Gene 182, 129-135.

Åslund, F. \& Beckwith, J. (1999). The thioredoxin superfamily: redundancy, specificity, and gray-area genomics. J Bacteriol 181, 1375-1379.

Beaven, G. H., Chen, S. H., Albis, A. D. \& Gratzer, W. B. (1974). A spectroscopic study of the haemin-human-serum-albumin system. Eur J Biochem 41, 539-546.

Bebbington, K. J. \& Williams, H. D. (1993). Investigation of the role of the $c y d D$ gene product in production of a functional cytochrome $d$ oxidase in Escherichia coli. FEMS Microbiol Lett 112, 19-24.

Beckman, D. L., Trawick, D. R. \& Kranz, R. G. (1992). Bacterial cytochrome $c$ biogenesis. Genes Dev 6, 268-283.

Bolhuis, H., van Veen, H. W., Molenaar, D., Poolman, B., Driessen, A. J. \& Konings, W. N. (1997). Mechanisms of multidrug transporters. FEMS Microbiol Rev 21, 55-84.

Cannon, J. B., Kuo, F.-S., Pasternack, R. F., Wong, N. M. \& MullerEberhard, U. (1984). Kinetics of the interaction of hemin liposomes with heme binding proteins. Biochemistry 23, 3715-3721.

Delaney, J. M., Wall, D. \& Georgopoulos, C. (1993). Molecular characterization of the Escherichia coli htrD gene: cloning, sequence, regulation, and involvement with cytochrome $d$ oxidase. J Bacteriol 175, 166-175.

Gennis, R. B. \& Stewart, V. (1996). Respiration. In Escherichia coli and Salmonella typhimurium: Cellular and Molecular Biology, 2nd edn, .pp. 217-261. Edited by F. C. Niedhardt and others. Washington, DC: American Society for Microbiology.

Georgiou, C. D., Fang, H. \& Gennis, R. B. (1987). Identification of the $c y d C$ locus required for expression of the functional form of the cytochrome $d$ terminal oxidase complex in Escherichia coli. J Bacteriol 169, 2107-2112.

Goldman, B. S., Gabbert, K. K. \& Kranz, R. G. (1996). Use of heme reporters for studies of cytochrome biosynthesis and heme transport. J Bacteriol 178, 6338-6347.

Goldman, B. S., Beckman, D. L., Bali, A., Monika, E. M., Gabbert, K. K. \& Kranz, R. G. (1997). Molecular and immunological analysis of an $\mathrm{ABC}$ transporter complex required for cytochrome $c$ biogenesis. J Mol Biol 268, 724-738.

Goldman, B. S., Beck, D. L., Monika, E. M. \& Kranz, R. G. (1998). Transmembrane heme delivery systems. Proc Natl Acad Sci USA 95, 5003-5008.

Grove, J., Tanapongpipat, S., Thomas, G., Griffiths, L., Crooke, H. \& Cole, J. (1996). Escherichia coli K-12 genes essential for the synthesis of c-type cytochromes and a third nitrate reductase located in the periplasm. Mol Microbiol 19, 467-481.

Haddock, B. A. \& Schairer, H. U. (1973). Electron transport chains of Escherichia coli Reconstitution of respiration in a $\delta$-aminolaevulinic acid-requiring mutant. Eur J Biochem 35, 34-45.

Henderson, D. P. \& Payne, S. M. (1994). Vibrio cholerae iron transport systems: roles of heme and siderophore iron transport in virulence and identification of a gene associated with multiple iron transport systems. Infect Immun 62, 5120-5125.

Higgins, C. F. (1992). ABC transporters - from microorganisms to man. Annu Rev Cell Biol 8, 67-113.

Higgins, C. F. \& Gottesman, M. M. (1992). Is the multidrug transporter a flippase? Trends Biochem Sci 17, 18-21.

Hrkal, Z., Vodrazka, Z. \& Kalousek, I. (1974). Transfer of heme from ferrihemoglobin and ferrihemoglobin isolated chains to hemopexin. Eur J Biochem 43, 73-78.

Hwang, P. K. \& Greer, J. (1980). Interaction between hemoglobin subunits in the hemoglobin-haptoglobin complex. J Biol Chem 255, 3038-3041.

Kita, K., Konishi, K. \& Anraku, Y. (1984). Terminal oxidases of Escherichia coli aerobic respiratory chain. I. Purification and properties of cytochrome $b_{562}-O$ complex from cells in the early exponential phase of aerobic growth. J Biol Chem 259, 3368-3374.

Light, W. R. \& Olson, J. S. (1990). Transmembrane movement of heme. J Biol Chem 265, 15623-15631.

McConville, M. L. \& Charles, H. P. (1979). Mutants of Escherichia coli K12 impermeable to hemin. J Gen Microbiol 113, 165-168.

McMurry, L., Petrucci, R. E. \& Levy, S. B. (1980). Active efflux of tetracycline encoded by four genetically different tetracycline resistance determinants in Escherichia coli. Proc Natl Acad Sci USA 77, 3974-3977.

Markwell, M. A., Haas, S. M., Bieber, L. L. \& Tolbert, N. E. (1978). A modification of the Lowry procedure to simplify protein determination in membrane and lipoprotein samples. Anal Biochem 87, 206-210.

Miller, J. H. (1972). Experiments in Molecular Genetics. Cold Spring Harbor, NY: Cold Spring Harbor Laboratory.

Osborne, J. P. \& Gennis, R. B. (1999). Sequence analysis of cytochrome $b d$ oxidase suggests a revised topology for subunit I. Biochim Biophys Acta 141, 32-50.

Page, M. D., Pearce, D. A., Norris, H. A. C. \& Ferguson, S. J. (1997). The Paracoccus denitrificans ccm A, $B$ and $C$ genes: cloning and sequencing, and analysis of the potential of their products to form 
a haem or apo- c-type cytochrome transporter. Microbiology 143, 563-576.

Poole, R. K. \& Hill, S. (1997). Respiratory protection of nitrogenase activity in Azotobacter vinelandii - roles of the terminal oxidases. Biosci Rep 17, 303-317.

Poole, R. K., Williams, H. D., Downie, J. A. \& Gibson, F. (1989). Mutations affecting the cytochrome $d$-containing oxidase complex of Escherichia coli K12: identification and mapping of a fourth locus, cydD. J Gen Microbiol 135, 1865-1874.

Poole, R. K., Hatch, L., Cleeter, M. W. J., Gibson, F., Cox, G. B. \& Wu, G. (1993). Cytochrome bd biosynthesis in Escherichia coli: the sequences of the $c y d C$ and $c y d D$ genes suggest that they encode the components of an ABC membrane transporter. Mol Microbiology 10, 421-430.

Poole, R. K., Gibson, F. \& Wu, G. (1994). The $c y d D$ gene product, component of a heterodimeric $\mathrm{ABC}$ transporter, is required for assembly of periplasmic cytochrome $c$ and of cytochrome $b d$ in Escherichia coli. FEMS Microbiol Lett 117, 217-224.

Pressman, B. C. (1976). Biological applications of ionophores. Annu Rev Biochem 45, 501-530.

Raina, S. \& Missiakis, D. (1997). Making and breaking disulfide bonds. Annu Rev Microbiol 51, 179-202.

Reid, E., Eaves, D. J. \& Cole, J. A. (1998). The CcmE protein from Escherichia coli is a haem-binding protein. FEMS Microbiol Lett 166, 369-375.

Rose, M. Y., Thompson, R. A., Light, W. R. \& Olson, J. S. (1985). Heme transfer between phospholipid membranes and uptake by apohemoglobin. J Biol Chem 260, 6632-6640.

Rosen, B. P. \& Tsuchiya, T. (1979). Preparation of everted membrane vesicles from Escherichia coli for the measurement of calcium transport. Methods Enzymol 56, 233-241.

Russel, M. \& Holmgren, A. (1988). Construction and characterization of glutaredoxin-negative mutants of Escherichia coli. Proc Natl Acad Sci USA 85, 990-994.

Russel, M. \& Model, P. (1988). Sequence of thioredoxin reductase from Escherichia coli. Relationship to other flavoprotein disulfide oxidoreductases. J Biol Chem 263, 9015-9019.

Russel, M., Model, P. \& Holmgren, A. (1990). Thioredoxin or glutaredoxin in Escherichia coli is essential for sulfate reduction but not for deoxyribonucleotide synthesis. J Bacteriol 172, 1923-1929.

Salmond, G. P. \& Reeves, P. J. (1993). Membrane traffic wardens and protein secretion in gram-negative bacteria. Trends Biochem Sci 18, 7-12.

Schulz, H., Hennecke, H. \& Thony-Meyer, L. (1998). Prototype of a heme chaperone essential for cytochrome $c$ maturation. Science 281, 1197-1200.

Schulz, H., Fabianek, R. A., Pellicioli, E. C., Hennecke, H. \& ThonyMeyer, L. (1999). Heme transfer to the heme chaperone CcmE during cytochrome $c$ maturation requires the $\mathrm{CcmC}$ protein, which may function independently of the ABC-transporter CcmAB. Proc Natl Acad Sci USA 96, 6462-6467.

Spinner, F., Cheesman, M. R., Thomson, A. J., Kaysser, T., Gennis, R. B., Peng, Q. Y. \& Peterson, J. (1995). The haem $b\left({ }_{558}\right)$ component of the cytochrome $b d$ quinol oxidase complex from Escherichia coli has histidine methionine axial ligation. Biochem J 308, 641-644.

Stewart, V. \& Parales, J. (1988). Identification and expression of genes narL and narX of the nar (nitrate reductase) locus in Escherichia coli K-12. J Bacteriol 170, 1589-1597.

Stojiljkovic, I. \& Hantke, K. (1992). Hemin uptake system of Yersinia enterocolitica: similarities with other TonB-dependent systems in Gram-negative bacteria. EMBO J 11, 4359-4367.

Stojiljkovic, I. \& Hantke, K. (1994). Transport of haemin across the cytoplasmic membrane through a haemin-specific periplasmic binding-protein-dependent transport system in Yersinia enterocolitica. Mol Microbiol 13, 719-732.

Stojiljkovic, I., Larson, J., Hwa, V., Anic, S. \& So, M. (1996). HmbR outer membrane receptors of pathogenic Neisseria spp: ironregulated, hemoglobin-binding proteins with a high level of primary structure conservation. J Bacteriol 178, 4670-4678.

Thanassi, D. G., Cheng, L. W. \& Nikaido, H. (1997). Active efflux of bile salts by Escherichia coli. J Bacteriol 179, 2512-2518.

Thöny-Meyer, L. (1997). Biogenesis of respiratory cytochromes in bacteria. Microbiol Mol Biol Rev 61, 337-376.

Thöny-Meyer, L., Ritz, D. \& Hennecke, H. (1994). Cytochrome $c$ biogenesis in bacteria: a possible pathway begins to emerge. Mol Microbiol 12, 1-9.

Throne-Holst, M., Thony-Meyer, L. \& Hederstedt, L. (1997). Escherichia coli $\mathrm{ccm}$ in-frame deletion mutants can produce periplasmic cytochrome $b$ but not cytochrome $c$. FEBS Lett 410, 351-355.

Tompkins, G. R., Wood, D. P. \& Birchmeier, K. R. (1997). Detection and comparison of specific hemin binding by Porphyromonas gingivalis and Prevotella intermedia. J Bacteriol 179, 620-626.

Torres, A. G. \& Payne, S. M. (1997). Haem iron-transport system in enterohaemorrhagic Escherichia coli O157: H7. Mol Microbiol 23, 825-833.

Received 11 August 1999; revised 5 November 1999; accepted 8 November 1999. 